\title{
Mycotoxin production profiles of the genus Penicillium fungi, isolated from the various environments.
}

\author{
Anatoly G. Kozlovsky*, Ol'ga E. Marfenina**, Natali G. Vinokurova*, \\ Valentina P. Zhelifonova* and Vladimir M. Adanin*
}

(Received July 24, 1997 ; Accepted July. 13, 1998)

\author{
Anatoly G. Kozlovsky*, Ol'ga E. Marfenina**, Natali G. Vinokurova*, \\ Valentina P. Zhelifonova* and Vladimir M. Adanin*：環境より分離されたペニシリ \\ ウム属真菌のマイコトキシン産生像
}

\begin{abstract}
Summary
Using spectral and chromatography methods mycotoxin production profiles were exanlined for 19 strains of 12 species of the genus Penicillium fungi. The mycotoxin profiles of the fungi, belonging to $P$. aurantiogriseum, P. chrysogenum. P. granulatum, P. spinulosum and P. vulpinum species, which were isolated from the various environments at various times, are differed from those, described earlier. Isolates of P. chrysogenum, P. griseofulvum and P. vulpinum produce the alkaloid nature mycotoxins, which were characteristic for these species. Mycofoxins were not detected in P. glabrum, P. dangeardii and P. funiculosum species.
\end{abstract}

Key words : Fungi, Penicillium. Mycotoxins, Structure confirmation, Ecosystems

In recent years it has been established that under the influence of anthropogenic factors for example various types of urban industrial and agricultural pollution and the disturbance of vegetation, etc, changes have been observed in the microbial cornmunites, especially in soil filamentous fungi.

As a result of these processes, microbial communities, rearrange themselves and the diversity of microfungal comunities decreases because of a decrease in the number of rare species ${ }^{1}$.

Simultaneously, the number and the abundance of some widespread species, including representatives of the genus Penicillium with phytotoxic properties, increases ${ }^{2,3}$.

Besides this, mycotoxin production may be stimulated as a result of the mutagenesis induced by xenobiotics and other pollutants of the environment ${ }^{4)}$. However, the data devoted to examination of the toxigenic potential of the fungi isolated from the ecosystems with anthropogenic stress, is very scanty ${ }^{5}$.

It is known, that the most number of the fungal strains occurred in the environment, belonging to the genus Penicillium (30\%) ${ }^{6}$. The final object of our study is to clear the difference between the mycotoxin productivity of the fungi grown in unpolluted ecosystems and that grown in the polluted ones.

The aim of this work as the first stage of our study is to investigate the mycotoxin production

* Institute of Biochemistry and Physiology of Microorganism, Russian Academy of Science (Pushchino, Moscow region, 142292, Russia)

** Science Faculty, Moscow State University (Moscow, 119899, Russia) 
profiles of the genus Penicillium fungi, which were isolated earlier from the various environments at various times, and to evaluate of their toxigenic potentional.

\section{Materials and Methods}

Fungi The following 19 isolates of the genus Penicillium, obtained from the Culture Collection of the Soil Science Faculty, Moscow State University, were used : P. aurantiogriseum Dierckx N3 (urban environment, Moscow, town soil, isolated 1993) ; P. chrysogenum Thom N4 (urban environment, home dust, 1994), N105 (primitive alpine soil, Pamir, 1987); P. dangeardii Pitt N1 (sod-podzolic soil, polluted by acid rain, 1993) ; P. funiculosum Thom N5 (urban environment, home dust, 1994), N7 (sod-podzolic soil, polluted by Pb, 1993), N9 (polar podzolic soil, Kola peninsula, 1994), N11 (chernozem, polluted by oilfuel, 1993), N146 (chernozem, polluted by pesticlde "Fundazol",*** 1993) ; P. glabrum (Wehmer) Westling N8 (polar humus podzolic soil, Kola peninsula, 1994), N10 (sod-podzolic soil, polluted by acid rain, 1993) ; P. granulatum Bainier N128 (sod-podzolic soil, Moscow, 1964) ; P. griseofulvum Dierckx N142 (typical chernozem soil, polluted by "Fundazol", 1993); P. implicatum Biourge N114 (serozem, Turkmenistan, 1978); $P$. janczewskii Zaleski N2 (sod-podzolic soil, polluted by acid rain, 1993); P. sp. N145 (typical chernozem, polluted by "Fundazol", 1993); P. spinulosum Thom N15 (urban environment, Moscow, 1993) ; P. vulpinum Seifert \& Samson (P. claviforme Cooke \& Massee), N16 (urban environment Moscow, snow, 1996), N113 (urban environment, Moscow, 1995). Identification of the species was done as described by Pitt ${ }^{7)}$.

Media and culture conditions Spores from 7-10 days-old malt agar slopes were used for inoculation. They were cultivated in submerged conditions $\left(24^{\circ} \mathrm{C}\right.$, a rotary shaker, $\left.220-240 \mathrm{rpm}\right)$ in $750 \mathrm{ml}$ Erlenmeyer flasks, containing $150 \mathrm{ml}$ modified Abe's medium of the following composition (g/1 distilled water) : mannitol -50 , succinic acid -5.4 (adjusted to $\mathrm{pH} 5.4$ using 25\% ammonia), $\mathrm{MgSO}_{4}$. $7 \mathrm{H}_{2} \mathrm{O}-0.3$ and $\mathrm{KH}_{2} \mathrm{PO}_{4}-1$.

Isolation and identification of the secondary metabolites

Metabolites were isolated from the culture broth on the 6-12 days of the growth as described $^{8)}$. Analysis of the metabolites was made by TLC on Silufol plates (Cavalier, Czech Republic). The following systems were used : chloroform-methanol-25\% ammonia (90: $10: 0.1$, v/v) (1) ; ethyI acetate-methanol-25\% ammonia ( $85: 15: 10)$ (2); toluene-ethyl acetate-formic acid $(5: 4: 1)$ (3) ; chloroform-acetone $(9: 1)$ (4). Systems $1-2$ were used for clavine and diketopiperazine alkaloids and $\boldsymbol{\alpha}$-cyclopiazonic acid (CPA), system 3 - for patulin, and system 4 for griseofulvin and cyclopenin. Alkaloids were detected as the absorbed zones in UV Iight or as coloured spots after spraying a plate with appropriate reagents ${ }^{5}$.

Authentic samples of the secondary metabolites were isolated and described earlier in the Laboratory of Biosynthesis of the Biologically Active Compounds, Insitute of Biochemistry and Physiology of Microonganisms, Russian Academy of Sciences: fellutanine A from $P$. fellutanum $^{9)}$, roquefortine, 3,12-dihydroroquefortine, isofumigaclavine A, isofumigaclavine $\mathrm{B}$, festuclavine from P. roquefort $i^{8}$, glandicoline, A, glandicoline B, meleagrin from P. glandicola

"Fundazol" (benomyl, uzgen, benlat, agrocit) : methyl-1-(butylcarbamoyl)-2-benzimidazolecarbamate, a very effective fungicide against a wide range of the deseases of the vegetable, fruit, field and decorative plants. 
var. glandicola ${ }^{10)}$, fumigaclavine $\mathrm{A}$, fumigaclavine $\mathrm{B}$, pyroclavine from $P$. palitans ${ }^{11)}$ and cyclopenin from the former also ${ }^{12)}$, epoxyagroclavine-I from $P$. corylophilum ${ }^{13)}$, griseofulvin, 16-N-ethylroquefortine, patulin from $P$. janczewski $i{ }^{14}$, aurantioclavine from $P$. aurantiovirens ${ }^{15)}$ and $\boldsymbol{\alpha}$-CPA from $P$. cyclopium ${ }^{5}$. These samples were used for confirmation of the structures of the investigated fungal metabolites, including TLC cochromatography.

Quantitative analysis was performed by UV-spectrophotometry after elution of the absorbed zones from the plates.

We have obtained the mixed fusion tests for fellutanine A, fumigaclavine A, fumigaclavine $\mathrm{B}$, pyroclavine, roquefortine. meleagrin and $\alpha$-CPA. No depressions of the melting points were observed.

The UV spectra of the metabolites in $\mathrm{MeOH}$ were recorded in a Shimadzu UV-160A spectrophotometer (Japan). The mass spectra were registered with a high-resolution Finnigan MAT 8430 mass spectrometer (Germany).

\section{Results and Discussion}

The examined species were isolated from the areas with the various environmental conditions at various times. The main part of the strains was isolated from the plots exposed by a high level of the anthropogenic impact - from urban soils, soils polluted by lead, acid rain, oilfuel and pesticide "Fundazol". Some strains were isolated from the extreme natural conditions from the polar soils (Kola peninsula), primitive alpine soils (Pamir) and light serozem (gray desert soil) (Turkmenistan). Besides that the fungal isolates from the snow of urbanized areas and from the dust of the flats in dwelling houses (Moscow) were investigated. All of the species were chosen on the basis of the preliminary analysis of the general complex of the filamentous fungi in the locations and were typical for them.

It is known, that the quantity of the fungal secondary metabolites produced, including mycotoxins, and the relationship between them depends on the culture conditions ${ }^{12}$. However, the qualitative composition of the metabolites is constant as a rule ${ }^{12.18)}$. Therefore, in the most cases submerged cultivation of the producer in the Abe's medium with mannitol and succinate as the sources of carbon and energy, favourable for a production of the secondary metabolites, allows us to study the main mycotoxins, produced by strains under examination.

Our attention was paid to indole containing alkaloids such as clavines and diketopiperazines as well as to O-heterocyclic compounds, to patulin and griseofulvin, which possess phytotoxic and antibiotic activities ${ }^{17.22)}$, and to benzodiazepine alkaloids of the cyclopenin group. Structure elucidation and confirmation of the metabolites were done by a complex of the spectral and chromatography methods, using : UV- and mass-spectra, mixed fusion tests and cochromatography with authentic samples. Detection of the compounds on the Silufol plafes was done with specific group reagents. A list of the main metabolites we found and their several physicochemical characteritics as follows:

$P$. aucantiogriseum N3

Fellutanine A: Colorless needles, mp (dec.) $270-272^{\circ} \mathrm{C}$ (from $\mathrm{MeCN}$ ). EI-MS m/z: $372.1605\left(\mathrm{M}^{+}\right.$, 372.1586 for $\mathrm{C}_{22} \mathrm{H}_{20} \mathrm{~N}_{4} \mathrm{O}_{2}$ ), 372 (rel. int., 15), 130 (100), 103 (6), 77 (7). UV $\lambda_{\max } n m: 223,272,280,290$. 
Rf 0.21 (sys. 1), 0.66 (sys. 2).

P. chrysogenum N105

16-N-ethylroquefortine: EI-MS m/z : $417.2137\left(\mathrm{M}^{+}, 417.2164\right.$ for $\left.\mathrm{C}_{24} \mathrm{H}_{27} \mathrm{~N}_{5} \mathrm{O}_{2}\right), 417$ (39), $348(100)$, 157 (16), 136 (34), 130 (28). UV $\lambda_{\max } \mathrm{nm}: 243,318$. Rf 0.41 (sys. 1), 0.73 (sys. 2).

Roquefortine: Colorless needles, $\mathrm{mp}$ (dec.) $194-198^{\circ} \mathrm{C}$ (from aq. $\mathrm{MeOH}$ ). EI-MS m/z : $389.1937\left(\mathrm{M}^{+}\right.$, 389.1851 for $\mathrm{C}_{22} \mathrm{H}_{23} \mathrm{~N}_{5} \mathrm{O}_{2}$ ), 389 (33), 320 (100), 157 (35), 130 (64), 108 (17). UV $\lambda_{\max } \mathrm{nm}: 238,325$. Rf 0.36 (sys. 1), 0.64 (sys. 2).

3.12-Dihydroroquefortine: EI-MS m/z $391.2021\left(\mathrm{M}^{+}, 391.2008\right.$ for $\left.\mathrm{C}_{22} \mathrm{H}_{25} \mathrm{~N}_{5} \mathrm{O}_{2}\right), 391$ (37), 322, (100), 294 (49), 130 (54), 110 (53). UV $\lambda_{\max } \mathrm{nm}: 244,301$. Rf 0.26 (sys. 1), 0.51 (sys. 2).

Glandicoline A : EI-MS m/z : $403.1618\left(\mathrm{M}^{+}, 403.1644\right.$ for $\left.\mathrm{C}_{22} \mathrm{H}_{21} \mathrm{~N}_{5} \mathrm{O}_{3}\right), 403$ (32), 335 (56), 307 (49), 306 (100). UV $\lambda_{\max } \mathrm{nm}: 230,286,344$. Rf 0.14 (sys. 1), 0.34 (sys. 2).

Glandicoline B : EI-MS m/z : $419.1603\left(\mathrm{M}^{+}, 419.1593\right.$ for $\left.\mathrm{C}_{22} \mathrm{H}_{21} \mathrm{~N}_{5} \mathrm{O}_{4}\right), 419$ (54), 403 (37), 351 (95), 335 (56), 306 (100). UV $\lambda_{\max } n m: 230,286,345$. Rf 0.17 (sys. 1), 0.39 (sys. 2).

P. chrysogenum N4

Fumigaclavine A : Colorless needles, mp (dec.) $81-82^{\circ} \mathrm{C}$ (from aq. $\mathrm{MeOH}$ ). EI-MS m/z: 298.1740 $\left(\mathrm{M}^{+}, 298.1681\right.$ for $\mathrm{C}_{18} \mathrm{H}_{22} \mathrm{~N}_{2} \mathrm{O}_{2}$ ), 298 (43), 239 (100), 181 (6) 154 (18), 144 (19). UV $\lambda_{\max } \mathrm{nm}: 224,273$, 281, 291. Rf 0.62 (sys. 1), 0.81 (sys. 2). Isofumigaclavine A (standard sample) : Rf 0.65 (sys. 1), 0.78 (sys. 2).

Fumigaclavine B : Colorless needles, $\mathrm{mp}$ (dec.) $240-242^{\circ} \mathrm{C}$ (from hexane-EtOH). EI-MS m/z : 256. $1611\left(\mathrm{M}^{+}, 256.1575\right.$ for $\left.\mathrm{C}_{16} \mathrm{H}_{20} \mathrm{~N}_{2} \mathrm{O}\right), 256$ (100), 289 (79), 181 (12), 154 (47), 144 (21). UV $\lambda_{\max } \mathrm{nm}: 223$, 274, 281, 291. Rf 0.22 (sys. 1), 0.74 (sys. 2). Isofumigaclavine B (standard sample) : Rf 0.27 (sys. 1), 0.66 (sys. 2).

Pyroclavine: Colorless needles, $\mathrm{mp}$ (dec.) $204-205^{\circ} \mathrm{C}$ (from $\left.\mathrm{C}_{6} \mathrm{H}_{14}-\mathrm{EtOH}\right) . \quad$ EI-MS m/z : 240.1696 $\left(\mathrm{M}^{+}, 240.1626\right.$ for $\mathrm{C}_{16} \mathrm{H}_{20} \mathrm{~N}_{2}$ ), 240 (100), 197 (24), 182 (10), 154 (24), 144 (35) . UV $\lambda_{\max } \mathrm{nm}: 223,273$, 280, 291. Rf 0.44 (sys. 1). Festuclavine, epicostaclavine and costaclavine (standard samples) : Rf $0.36,0.32$ and 0.20 , respectively (sys. 1 ).

\section{P.granulatum N128}

Roquefortine and 3, 12-dihydroroquefortine were identified (data not shown).

Meleagrin: Pale yellow leaves, $\mathrm{mp}$ (dec.) $248-249^{\circ} \mathrm{C}$ (from $\mathrm{CHCl}_{3}$ ).

EI-MS m/z : $433.1777\left(\mathrm{M}^{+}, 488.1750\right.$ for $\left.\mathrm{C}_{23} \mathrm{H}_{23} \mathrm{~N}_{5} \mathrm{O}_{4}\right), 433$ (35), 365 (100), 318 (43), 305 (63), 277 (71). UV $\lambda_{\max } \mathrm{mn}: 230,286,348$. Rf 0.44 (sys. 1), 0.48 (sys. 2).

P. griseofulvum N142

Roquefortine (data not shown).

P. implicatum N114

Epoxyagroclavine-I : EI-MS m/z : $254.1431\left(\mathrm{M}^{+}, 254.1419\right.$ for $\left.\mathrm{C}_{16} \mathrm{H}_{18} \mathrm{~N}_{2} \mathrm{O}\right), 254$ (100), 239. (41), 211 (71), 196 (31), 154 (74). UV $\lambda_{\max } \mathrm{nm}: 224,275,281,291$. Rf 0.50 (sys. 1).

P. janczewskii $\mathrm{N} 2$

Griseofulvin: $\mathrm{mp}$ (dec.) $220-221^{\circ} \mathrm{C}$. EI-MS m/z : $352.0725\left(\mathrm{M}^{+}, 352.0713\right.$ for $\left.\mathrm{C}_{17} \mathrm{H}_{17} \mathrm{O}_{6} \mathrm{Cl}\right), 352(100)$, 321 (56), 310 (58), 215 (57), 138 (86). UV $\lambda_{\max } \mathrm{nm}: 235$, 252, 291, 324. Rf 0.63 (sys. 4).

P. sp. N145

Cyclopenin: EI-MS m/z : $294.1014\left(\mathrm{M}^{+}, 294.1004\right.$ for $\left.\mathrm{C}_{17} \mathrm{H}_{14} \mathrm{~N}_{2} \mathrm{O}_{3}\right), 294$ (100), 161 (82), 146 (27), 119 
(82), 92 (43). UV $\lambda_{\max } \mathrm{nm}: 285$. Rf 0.40 (sys. 4).

\section{P. spinulosum N15}

Cyclopenin, roquefortine and fellutanine A were identified (data not shown).

P. vulpinum N16

Roquefortine, 3, 12-dihydroroquefortine, aurantioclavine were identified (data not shown).

P. vulpinum N113

$\alpha$-CPA : Needles, mp 243-245 ${ }^{\circ} \mathrm{C}$ (from MeOH). EI-MS m/z : $336.1508\left(\mathrm{M}^{+}, 336.1473\right.$ for $\mathrm{C}_{20} \mathrm{H}_{20} \mathrm{~N}_{2}$ $\mathrm{O}_{3}$ ), 336 (70), 196 (52), 182 (100), 181 (54), 154 (50). UV $\lambda_{\max } \mathrm{nm}: 223,253,273$ sh., 284, 293 sh. $\mathrm{Rr} 0.22$ (sys. 1), 0.40 (sys. 2).

$\boldsymbol{\alpha}$-CPA imine: EI-MS m/ z : $335.1694\left(\mathrm{M}^{+}, 335.1633\right.$ for $\left.\mathrm{C}_{20} \mathrm{H}_{21} \mathrm{~N}_{3} \mathrm{O}_{2}\right) 335$ (41), 196 (40), 181 (49), 180 (100), 154 (21). UV $\lambda_{\max } \mathrm{nm}: 224,245$ sh., 275 sh., 286 sh., 292. Rf 0.40 (sys. 1), 0.75 (sys. 2).

All of these characteristics are identical with those for these metabolites, described earlier ${ }^{5,8-15)}$. But we consider this time the differences between characteristics of the fungi isolated earlier and later, and between those isolated at the anthropogenically-active and inactive places as described below.

On the basis of the obtained data, it was shown, that the most toxins were produced by the strains belonging to $P$. chrysogenum, P. granulatum, P. spinulosum, P. vulpinum species. It is necessary to point out that several strains including $P$. aurantiogriseum $\mathrm{N} 3, P$. chrysogenum $\mathrm{N} 4$, P. spinulosum N15 and P. vulpinum N113, were able to produce the mycotoxins, which were unknown before for these species.

For instance, $P$. chrysogenum species is known as a producer of such mycotoxins as penicillin, ruguluvasine and diketopiperazine alkaloids of the roquefortine group ${ }^{16,17,19)}$. In our case strain N105, isolated from primitive Pamir alpine soil, produces alkaloids of the roquefortine group. But another strain of this species - N4, isolated from the home dust, produced a considerable quantity (up to $10 \mathrm{mg} / 1$ ) clavine alkaloids (fumigaclavine A, fumigaclavine B and pyroclavine) unknown before for representatives of this species.

P. vulpinum N113 (P. claviforme), isolated from the urban environment, showed a high production of $\boldsymbol{\alpha}$-CPA and its imine. Roquefortine, oxaline, viridicatine, cyclopenin and patulin, described for this species ${ }^{16}$, were not detected in this strain. On the other hand strain N16, isolated from the snow of the Moscow downtown, produced roquefortine, which is characteristic for the typical strains of this species.

$P$. granulatum is known as a producer of such mycotoxins as patulin, viridicatin and roquefortine ${ }^{18-20)}$. The strain N128 was characterized by a high production (up to $10 \mathrm{mg} / \mathrm{l}$ of the culture broth) of alkaloids of the roquefortine group - meleagrin, roquefortine, 3,12dihydroroquefortine. New producers of the tryptophyltryptophyldiketopiperazine (fellutanine A) - P. spinulosum N15 and P. aurantiogriseum N3 were found. Both strains were isolated from the urban environment. Recently fellutanine A was found in the strain P. fellutanum VKM F- $3020^{9)}$.

P. janczewskii is well-known as a producer of griseofulvin ${ }^{17)}$, which was also produced by strain P. janczewskii N2.

In our studies the strains belonging to the species $P$. glabrum, $P$. dangeardii, $P$. funiculosum 
have not shown the ability to produce a visible quantity of the secondary metabolites. It is necessary to point out, that in the literature, also, these strains do not belong to the group of active producers of mycotoxins ${ }^{16,17,19}$.

It was established, that examined strains of P.aurantiogriseum, P. chrysogenum, $P$. granulatum, $P$. spinulosum and $P$. vulpinum are able to produce another profiles of the secondary metabolites then described for them in the literature. Among them such mycotoxins, as $\boldsymbol{\alpha}$ cyclopiazonic acid and clavine alkaloids, are present. The most toxigenic potential was characteristic for isolates $P$. vulpinum N113 (content of $\boldsymbol{\alpha}$-CPA, up to $100 \mathrm{mg} / \mathrm{l}$ ) and $P$. chrysogenum N4 (content of clavine alkaloids, up to $10 \mathrm{mg} / \mathrm{l}$ ).

Our results have an ecotoxicological significance inasmuch as the fungal producers of mycotoxins examined in our studies are becoming typical and dominant in microfungal communities in the ecosystems which are experiencing human impact ${ }^{23)}$.

Acknowledgement This work was supported by a grant of the Russian Found of the Fundamental Investigation (RFFI) N96-04-49264.

\section{References}

1) Marfenina O. E. : Eurasian Soil Science, 26/6, 115-123 (1994).

2) Levin S. V., Gusev V. S., Aseeva I. V.: Microorganisms and soils protection (in Russian). Moscow, Moscow State University, 5, 18-19 (1989).

3) Marfenina O. E., Mirchink T. G. : Sovetskoe Pochvovedenie (in Russian), 21, 107-112 (1989).

4) Kurakov A. V., Popov A. I. : Pochvovedenie (in Russian), 3, 314-321 (1995).

5) Kozlovsky A. G., Solovyeva T. F., Bukhtiyarov Yu. E., Shurukhin Yu. V., Sakharovsky V. G., Adanin V. M., Nefedova M. Yu., Pertsova R. N., Tokarev V. G., Golovleva L. A. : Microbiologiya (in Russian), 59, 601-608 (1990).

6) Mirchink T. G.: Pochvennaya mycologiya. Moscow, Moscow State University, (in Russian), 220, 118120 (1988).

7) Pitt J. I.: A Iaboratory guide to common Penicillium species. Commonwealth scientific and industrial research organization. Division food processing. 187, 26-180 (1991).

8) Kozlovsky A. G., Reshetilova T. A., Medvedeva T. N., Arinbasarov M. U., Sakharovsky V. G., Adanin V. M. : Biokhimiya. (in Russian), 44, 1691-1700 (1979).

9) Kozlovsky A. G., Vinokurova N. G., Adanin V. M., Sedmera P.: Prikladnaya Biokhim. i Mikrobiol. (in Russian), 33, 409-415 (i997).

10) Kozlovsky, A. G., Vinokurova N. G., Reshetilova T. A., Sakharovsky V. G., Baskunov B. P., Seleznyov S. G.: Prikladnaya Biokhim. i Mikrobiol. (in Russian), 30, 410-414 (1994).

11) Vinokurova N. G., Reshetilova T. A., Adanin V. M., Kozlovsky A. G. Prikladnaya Biokhim. i Microbiol. (in Russian), 27, 850-866 (1991).

12) Vinokurova N. G., Reshetilova T. A., Yarchuk N. I., Adanin V. M., Kozlovsky A. G.: Prikladnaya Biokhim. i Mikrobiol. (in Russian) 29, 559-566 (1993).

13) Kozlovsky A. G., Solovyova T. F., Sakharovsky V. G., Adanin V. M. : Prikladnaya Biokhim. i Mikrobiol. (in Russian), 18, 535-541 (1982).

14) Kozlovsky A. G., Vinokurova N. G., Zhelifonova V. P., Adanin V. M.: Prikladnaya Biokhim. i Microbiol. (in Russian), 33, 70-74 (1997).

15) Kozlovsky A. G., Solovyova T. F., Sakharovsky V. G., Adanin V. M. : Proceedings of the USSR Academy of Sciences. (in Russian), 260, 230-233 (1981).

16) Frisvad J. C., Filtenborg O.: Mycologia. 81, 837-861 (1989).

17) Cole R. J., Cox R. H.: Handbook of toxin fungal metabolites. New. York: Acad. Press. 935, 537-544. (1981). 
18) Reshetilova T. A., Solov'yova T. F., Baskunov B. P., Kozlovsky A. G. : Mikrobiologiya (in Russian), 61, 873-879 (1992).

19) Reshetilova T. A., Kozlovsky A. G. : Prikladnaya Biokhimi Mikrobiol. (in Russian), 26, 291-306 (1990).

20) Ciegler A., Hou C. T. US Pat. N3, 666,680. (1972).

21) Frisvad J. C., Filtenborg O. Appl. Environ. Microbiol. 46,1301-1310 (1983).

22) Berestetskii O. A. : Phytotoxic properties of the soil metabolites. Moscow. VNIICHM. 245, 245-248 (1978)

23) Marfenina O. E., Karavaiko N. M., Ivanova A. E. : Microbiology (Trans. from "Mikrobiologiya" in Russian), 65, 105-110 (1996). 